\title{
Numerical Investigation of the Influences of Wellbore Flow on Compressed Air Energy Storage in Aquifers
}

\author{
Yi Li, ${ }^{1}$ Keni Zhang, ${ }^{2}$ Litang $\mathrm{Hu},{ }^{1}$ and Jinsheng Wang ${ }^{1}$ \\ ${ }^{1}$ College of Water Sciences, Engineering Research Centre of Groundwater Pollution Control and Remediation of \\ Ministry of Education, Beijing Normal University, Beijing 100875, China \\ ${ }^{2}$ Institute of Groundwater and Earth Sciences, Jinan University, Guangzhou 510632, China \\ Correspondence should be addressed to Litang Hu; litanghu@bnu.edu.cn
}

Received 7 July 2017; Accepted 8 October 2017; Published 31 October 2017

Academic Editor: Marco Petitta

Copyright (c) $2017 \mathrm{Yi} \mathrm{Li} \mathrm{et} \mathrm{al.} \mathrm{This} \mathrm{is} \mathrm{an} \mathrm{open} \mathrm{access} \mathrm{article} \mathrm{distributed} \mathrm{under} \mathrm{the} \mathrm{Creative} \mathrm{Commons} \mathrm{Attribution} \mathrm{License,} \mathrm{which}$ permits unrestricted use, distribution, and reproduction in any medium, provided the original work is properly cited.

\begin{abstract}
With the blossoming of intermittent energy, compressed air energy storage (CAES) has attracted much attention as a potential largescale energy storage technology. Compared with caverns as storage vessels, compressed air energy storage in aquifers (CAESA) has the advantages of wide availability and lower costs. The wellbore can play an important role as the energy transfer mechanism between the surroundings and the air in CAESA system. In this paper, we investigated the influences of the well screen length on CAESA system performance using an integrated wellbore-reservoir simulator (T2WELL/EOS3). The results showed that the well screen length can affect the distribution of the initial gas bubble and that a system with a fully penetrating wellbore can obtain acceptably stable pressurized air and better energy efficiencies. Subsequently, we investigated the impact of the energy storage scale and the target aquifer depth on the performance of a CAESA system using a fully penetrating wellbore. The simulation results demonstrated that larger energy storage scales exhibit better performances of CAESA systems. In addition, deeper target aquifer systems, which could decrease the energy loss by larger storage density and higher temperature in surrounding formation, can obtain better energy efficiencies.
\end{abstract}

\section{Introduction}

Compressed air energy storage (CAES) can be considered as a potential storage technology combined with intermittent energy sources (e.g., wind energy and solar energy). Compressed air is injected into a "storage vessel" using excess electricity and can be produced to generate electricity as needed [1-3]. The scale of the stored energy depends on the choice of the storage vessel. Porous rock reservoirs (aquifers) and cavern reservoirs (salt domes or caverns in hard rock) are candidates for large-scale storage vessels (Figure 1). The Huntorf plant in Germany (290 MW) and the McIntosh plant in the USA $(110 \mathrm{MW})$ are two existing commercial largescale compressed air energy storage plants $[4,5]$. They both use a salt dome (cavern reservoir) as the air storage vessel. Thermodynamic and hydrodynamic studies of compressed air energy storage in caverns (CAESC) have been conducted to describe the pressure and temperature variances [6-10].
Additionally, an advanced CAES system (adiabatic compressed air energy storage) with no reheating requirements to regenerate electricity has been investigated $[9,11-13]$.

Compressed air energy storage in aquifers (CAESA), which costs less and has a wider availability, is becoming more attractive compared with CAESC $[2,14]$. The feasibility of CAESA was investigated by Oldenburg and Pan using numerical modelling, which showed its energy efficiency well using the operation scheme in the Huntorf plant [15]. Later, they proposed and simulated the utilization of $\mathrm{CO}_{2}$ as a cushion gas for a CAESA system [16]. The impact factors on the variances of pressure and temperature have been studied, including the reservoir permeability, gas bubble volume, gas bubble boundary permeability, and geological structures and thicknesses [17-19]. In addition, the ranking criteria for candidate sites were suggested by Succar and Williams [2]. The Iowa Stored Energy Park (ISEP) planned to build a 270 MW CAESA plant, but the project had to be cancelled 


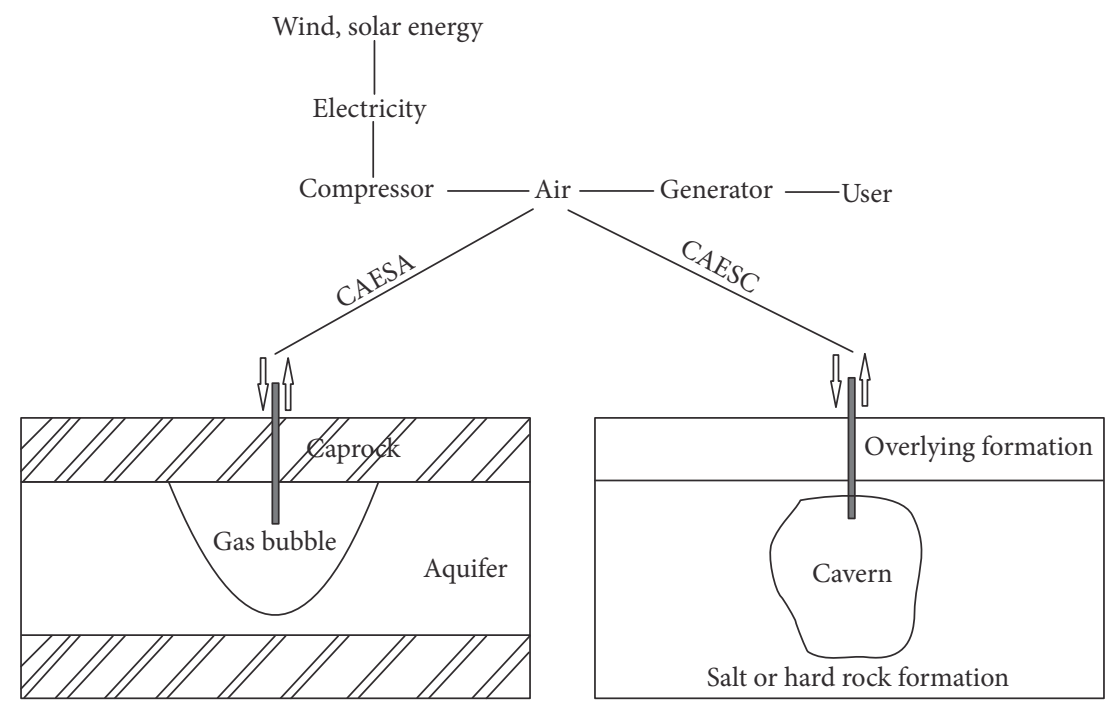

FIgURE 1: Schematic diagrams of CAESA and CAESC systems.

due to geological limitations [20]. The Pacific Northwest National Laboratory (PNNL) evaluated the technical and economic feasibility of CAESA in the Columbia Basin and designed a hybrid CAES plant that integrated geothermal energy [21].

Generally, the cyclic processes of compressed air can be divided into daily cycles and weekly cycles. Because compressed air is cyclically injected and produced frequently through the wellbore, the wellbore will play an important role in a CAESA system regarding the energy transfer from the formation and the energy deliverability. Kushnir et al. studied the relationship between the well screen length and water suction in CAESA, where the existence of an airwater interface was assumed in anticline structure. Their results showed that longer well screens can decrease pressure fluctuations while increasing the risk of water suction [22, 23]. Pan and Oldenburg developed a T2WELL simulator to integrate the wellbore and reservoir, and it has shown good performance when describing the wellbore-reservoir system in different fields, including $\mathrm{CO}_{2}$ geological sequestration, geothermal energy, and CAESA [24]. Li et al. investigated the heat transfer in a single wellbore by investigating CAESA using a semianalytical solution. Their studies were mainly concentrated on the thermodynamic analysis of the well section in the overlying impermeable formation and ignored the impacts of energy transfer in the target aquifer. Their study showed that the small wellbore overall heat transfer coefficient and thermal diffusivity of the formation can help to decrease the heat loss [25]. Meanwhile, the initial gas bubble make-up can also be influenced by the wellbore and affect the subsequent cycle processes. The make-up of the initial gas bubble is the first step in the operation of a CAESA system, during which the amount of air needs to be injected into the aquifer to displace the water to build a bubble. This gas bubble can provide the necessary pressure to keep the next operation of the cycle sustainable. In previous studies, the initial gas bubble was always assumed to be under ideal conditions, wherein the gas is fully saturated in the target storage space. However, this assumption is not practical in a CAESA system. Aimed at the studies concerning the initial gas bubble make-up, Guo et al. investigated the impact factors on the creation of the initial gas bubble, and TOUGH2/EOS3 was used to simulate the gas bubble creation [17]. However, their study was limited because their simulator was not sufficiently precise in describing the air flow in the wellbore, which is controlled by non-Darcian flow, and the well screen was simply fixed on the top of the aquifer.

Given the aforementioned gaps in the previous studies, we will study and analyse the effect of the wellbore on a CAESA system, thereby concentrating on the impact of the well screen length in the target aquifer. We will discuss the impact of the well screen length on the initial gas bubble formation and the CAESA system performance. On the basis of optimizing the well screen length configuration, we will also study the impacts of the energy storage scale and reservoir depth on the energy storage efficiency. Due to the lack of practical engineering applications of CAESA, numerical modelling is a valid method to study these key problems. The initial gas bubble make-up and subsequent cycle operations will be simulated using T2WELL/EOS3. The results will help to optimize the CAESA system.

\section{Model Setup}

2.1. Numerical Method. T2WELL is an integrated wellborereservoir simulator that can describe the nonisothermal, multiphase and multicomponent flow in a porous or fractured system. In the simulator, the drift-flux model is used to solve for the mixture flow within the wellbore, and the flow in the reservoir is described similarly as with TOUGH2 [26]. Different fluid state modules are integrated into T2WELL for applications in different fields. T2WELL/EOS3 was developed to describe a $\mathrm{H}_{2} \mathrm{O}$-air-heat system, which is appropriate for simulating the CAESA process [15]. In the EOS3 module, the 
air is considered as an ideal gas and the water properties are described by the steam table equations. The detailed mechanics process and chemical reaction process are not considered in the module. The selected three primary thermodynamic variables (pressure, air mass fraction, and temperature for single-phase and gas phase pressure, gas saturation, and temperature for two phases) can describe the system condition. The air dissolution in the water can be estimated by Henry's law, where the air pressure is proportional to air solubility in water (mol fraction dissolved in water) and the proportional constant is Henry's constant. Henry's constant slowly varies with temperature, so a constant is adopted in the module [26]. A comparison study of the simulation results from T2WELL/EOS3 with monitoring data from the Huntorf plant has shown the feasibility of the simulator application in previous studies [18].

\subsection{Numerical Model and Scheme Design}

2.2.1. Grid Design. A radial symmetric grid was created to describe the entire aquifer system in the CAESA system using the mesh generator Wingridder [27]. To eliminate boundary effects, the radial domain of the model covers $1000 \mathrm{~m}$ away from the centre wellbore. The thickness of target aquifer is set as $50 \mathrm{~m}$, which ranges from $-650 \mathrm{~m}$ to $-700 \mathrm{~m}$ with a grid resolution of $2 \mathrm{~m}$, and the formation above the aquifer is considered impermeable. The vertical resolution of the mesh is refined near the wellhead, as well as the interface between the overlying formation and the target aquifer. In the radial direction, the grid resolution varies from $0.25 \mathrm{~m}$ near the wellbore to $70 \mathrm{~m}$ in the far field. The diameter of the wellbore is set as $0.5 \mathrm{~m}$. Figure 2 and Table 1 show the profile of the radial symmetric mesh from $0 \mathrm{~m}$ to $200 \mathrm{~m}$ and the aquifer parameters, respectively. The van Genuchten-Mualem model and van Genuchten function are used for calculating the gas and liquid relative permeability and capillary pressure. The functions can be referred to in [26]. They both depend on the saturation (gas or liquid) in the latest time step and some other parameters (power in expression, aqueous phase residual saturation, gas phase residual saturation, capillary pressure strength between aqueous and gas phases, and maximum capillary pressure). The model is initially assumed to be fully water saturated. The distribution of the pressure is based on hydrostatic equilibrium, and the atmospheric pressure is set as that of the land surface. The temperature is initially calculated by the geothermal gradient $\left(38.5^{\circ} \mathrm{C} / \mathrm{km}\right)$ with a surface temperature of $15^{\circ} \mathrm{C}$. In addition, a constant lateral boundary condition is set during the entire process.

2.2.2. Scheme Design. A daily cycle operating scheme was more common in the previous studies. As no commercial CAESA plant exists, we choose the daily cycle based on Guo's research (the same as that in the Huntorf plant), which includes an injection stage $(12 \mathrm{~h})$, a shut-in stage $(4.5 \mathrm{~h})$, a production stage $(3 \mathrm{~h})$, and another shut-in stage $(4.5 \mathrm{~h})$ [17]. Meanwhile, a larger energy scale will be simulated compared with Guo's research. We design the operation cycle with an injection of $5 \mathrm{~kg} / \mathrm{s}$ and a production of $20 \mathrm{~kg} / \mathrm{s}$, which can

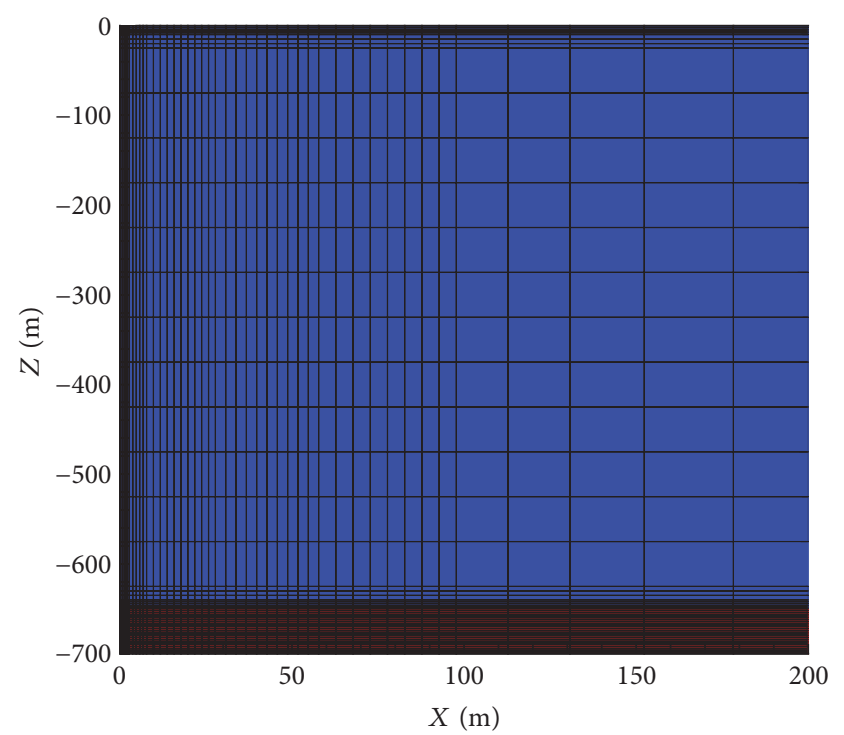

Figure 2: Profile of the radial symmetric mesh in a range of $200 \mathrm{~m}$ (blue represents the Caprock domain and red represents target domain).

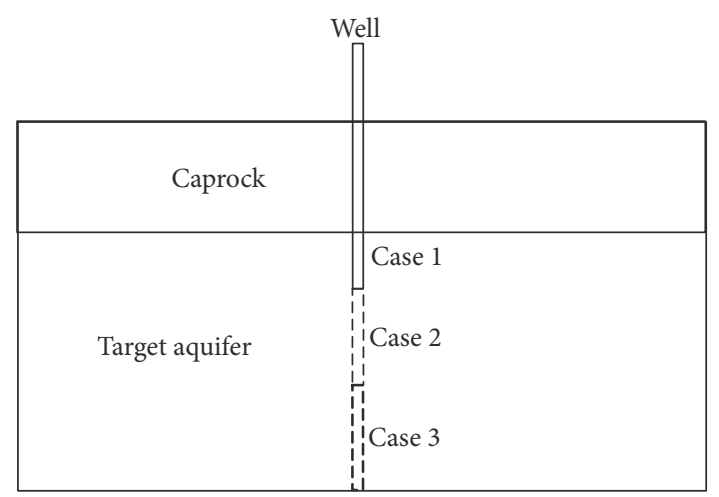

Figure 3: Schematic figure of the three cases with a different penetrating well to the target aquifer.

maintain the total gas mass balance. The enthalpy of injected air is $0.328 \mathrm{MJ} / \mathrm{kg}$. The injection and production processes adopt constant flow rate at the wellhead. The well is closed to mass flow transfer with surrounding formation along its length except where it is perforated, but the energy flow transfer exists along all length. In the simulation, the flow and energy transfer both in wellbore and between wellbore and reservoir can be detailedly described in [24]. In the initial stage of the gas bubble make-up, air is injected into the aquifer at $50 \mathrm{~kg} / \mathrm{s}$ for 30 days based on a preliminary model, which is used to estimate the initial gas volume consideration with the planned operation cycle scheme. To address the aforementioned questions about the well screen, three cases with different penetrating well screens will be developed in our model (Figure 3), which are $10 \mathrm{~m}$ penetration (Case 1), $30 \mathrm{~m}$ penetration (Case 2), and $50 \mathrm{~m}$ penetration (Case 3 ). 
TABLE 1: List of the key parameters of the aquifer.

\begin{tabular}{lcc}
\hline Parameters & Value & Unit \\
\hline Grain density & 2600 & $\mathrm{~kg} / \mathrm{m}^{3}$ \\
Permeability (horizontal) & $3.0 \times 10^{-13}$ & $3.0 \times 10^{-14}$ \\
Permeability (vertical) & 0.2 & $\mathrm{~m}^{2}$ \\
Porosity & $1.0 \times 10^{-10}$ & $\mathrm{~Pa}{ }^{-1}$ \\
Compressibility & 2.51 & $\mathrm{~W} /\left(\mathrm{m} \cdot{ }^{\circ} \mathrm{C}\right)$ \\
Heat conductivity & $\mathrm{J} /\left(\mathrm{kg} \cdot{ }^{\circ} \mathrm{C}\right)$ \\
Rock grain special heat & $\mathrm{van}$ Genuchten-Mualem model \\
Relative permeability function & van Genuchten function \\
Capillary pressure function & 0.60 \\
Power in expression & 0.12 \\
Aqueous phase residual saturation & 0.05 \\
Gas phase residual saturation & 675.68 \\
Capillary pressure strength between aqueous and gas phases & $5.0 \times 10^{5}$ \\
Maximum capillary pressure & \\
\hline
\end{tabular}

\section{Results and Analysis}

3.1. Initial Gas Bubble. After 30 days of air injection, an initial gas bubble is created for the three cases (Figure 4). The different penetrating cases result in the evolution of different shapes of the gas bubble. Considering the domain in which the gas saturation is larger than 0.5 after 30 days, Case 1 has a wider horizontal scale (increasing to approximately $60 \mathrm{~m}$ ) but has a smaller scale in the vertical direction (approximately $25 \mathrm{~m})$ when compared with those of Case $2(40 \mathrm{~m} \times 41 \mathrm{~m})$ and Case $3(25 \mathrm{~m} \times 50 \mathrm{~m})$. A decreasing well screen length can cause the gas bubble to trend along the horizontal direction, which may induce larger gas diffusion and pressure fluctuation during the operation cycle. The reason for this is that a short well screen has a small interface area for air that is being injected into the aquifer, and thus, the air tends to remain at the top and move horizontally owing to the buoyancy force and a high horizontal permeability.

The pressure will gradually decrease with time (Figure 5) and become stable with a continued injection time. It is easier to inject the same amount of gas with an increasing gas volume in the aquifer. The pressure will increase inversely with the length of the well screen, which can also be caused by the smaller interface area for gas injection into the aquifer. The maximum pressure at the wellhead will increase to over $22 \mathrm{MPa}$ for a short well screen (Case 1), during which any possible hazards caused by pressure build-up should be considered [28]. Also the high pressure during initial gas bubble injection process can change the permeability and porosity of aquifer near the wellbore [29], which may cause the subsequent injection pressure variance. In the practice engineering, the high build-up pressure in the initial gas bubble injection process can be avoided by possible injection method or process (e.g., constant pressure injection or the intermittent injection). The total amount of initial injection gas varies with the energy scale and characteristic of reservoir and also it depends on the economy. In the engineering practice, a prior model is needed to make a decision for the total amount of initial injection gas.

\subsection{Performance of the CAESA System}

3.2.1. Change of Pressure and Temperature in the CAESA System. Figure 6(a) shows the change in the wellhead pressure with time during the cycle processes in the three different penetrating cases. The maximum pressure with the short well screen length is higher than that with the longer well screen length cases. However, the minimum wellhead pressure during production is lower with a decrease in the well screen length, which is probably the result of a small area for gas flow during the injection and production process as a consequence of the short well screen length that penetrates into the target aquifer. In the same cycle scheme, the wellhead pressure needs to be higher in order to inject the necessary amount of gas; meanwhile, it needs to be lower to meet the required deliverability. Additionally, as the pressurized air is needed in order to regenerate electricity, the lower pressure during the production process with a shorter screen length may be not available.

Variances of the wellhead temperature with time during the operation cycle for the three cases are shown in Figure 6(b). In the first shut-in stage, the wellhead temperature decreases owing to the decompression of the air and the cooling of the wellhead temperature. In this stage, the wellhead temperature with a short screen length (Case 1) is lower than in the other two cases, which can be caused by a larger pressure reduction (Figure 6(a)). In the production stage, the decline in the wellhead temperature is caused by multiple factors, including air decompression, energy loss in the aquifer, and heat transfer between the well and the formation. During the production process, the air temperature at the wellhead (Case 1) is lower. As a higher background geothermal temperature occurs at deeper locations within the aquifer, the well 


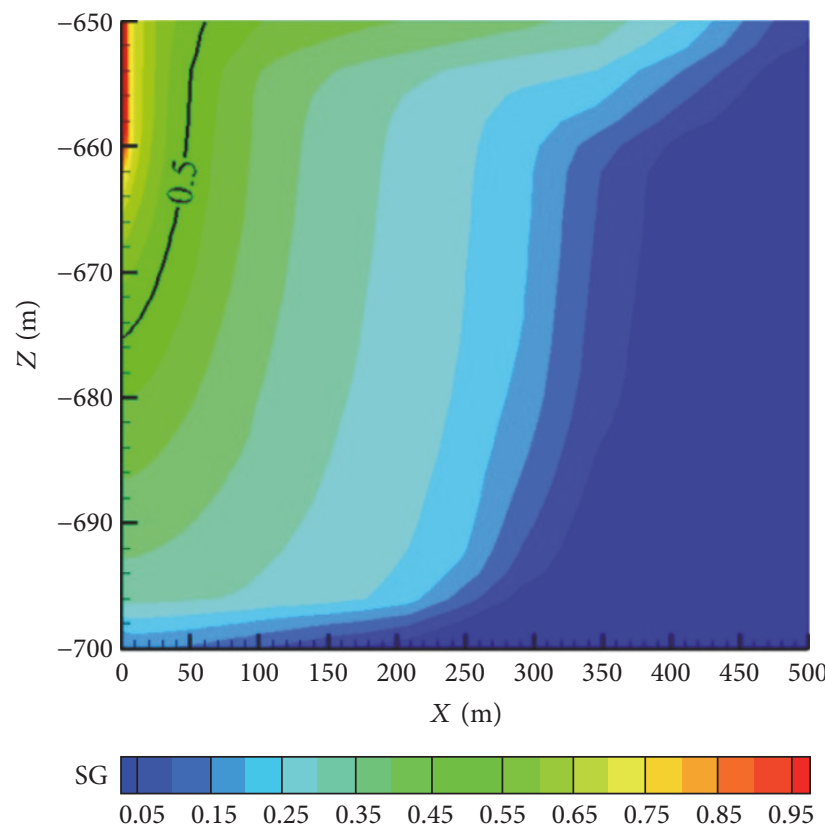

(a)

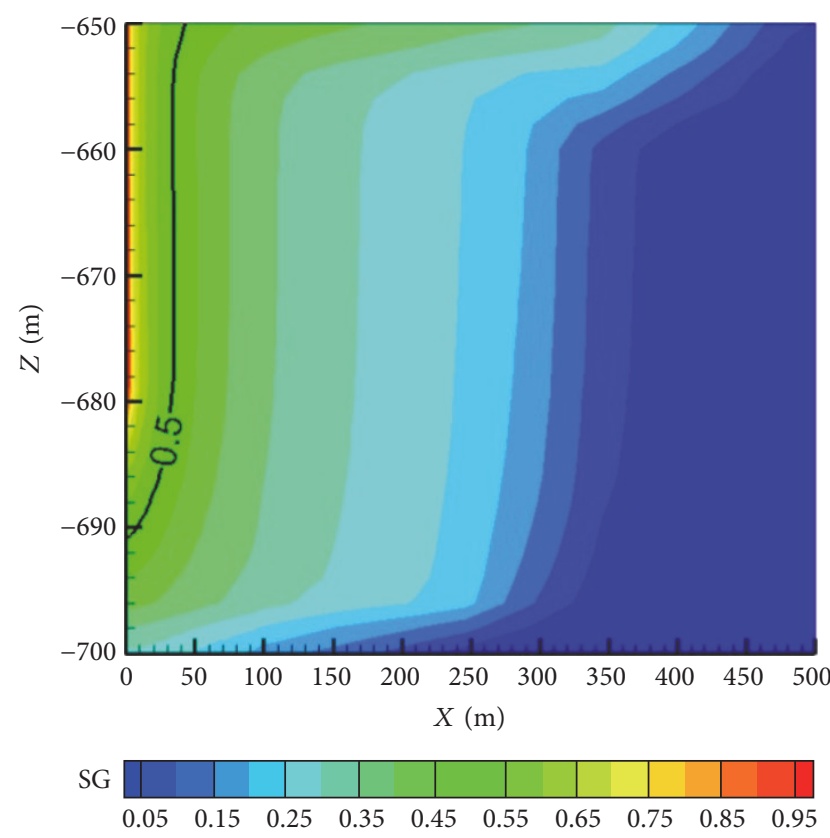

(b)

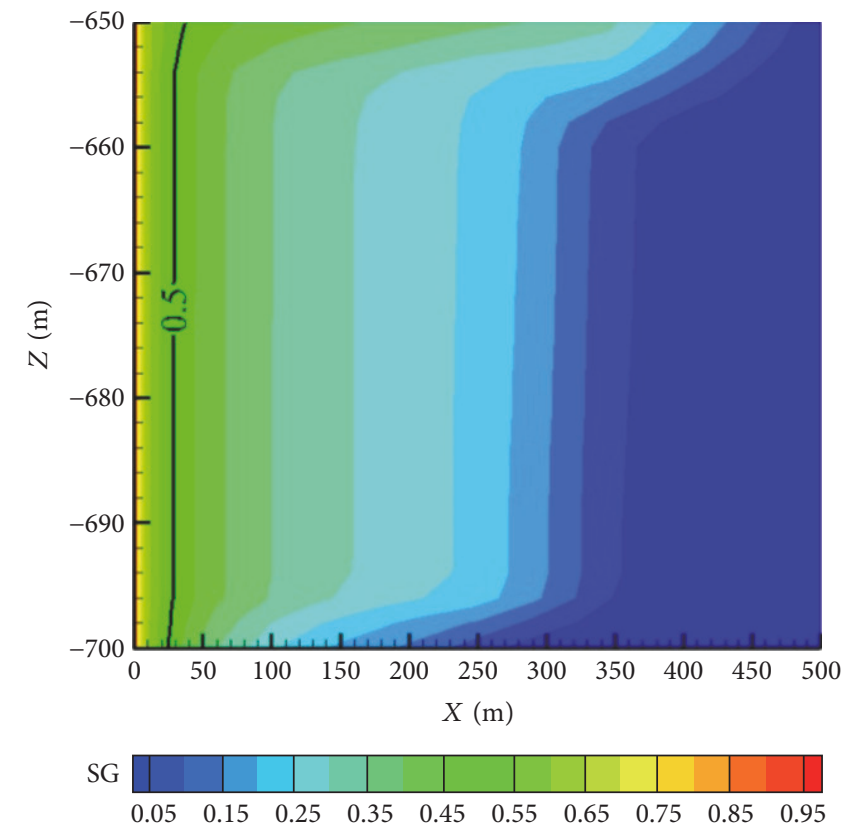

(c)

Figure 4: Gas saturation distribution for the three cases after a 30-day injection period in the aquifer. (a) Case 1 (10 m). (b) Case 2 (30 m). (c) Case $3(50 \mathrm{~m})$.

screen lengths used to penetrate the aquifer in Case 2 and Case 3 can reduce the heat loss and keep the temperature higher at the wellhead than that in Case 1. In the shut-in stage after production, the wellhead temperature increases due to the heat of compression caused by the wellhead pressure recovery phase, and an increase in the temperature will accompany a more prolonged pressure recovery stage (Case 1) (Figure 6(a)). Also, the variance differences in pressure and temperature among the three cases demonstrate the more sensitive to the shorter wellbore screen case. The variances are more obvious between Case 1 and Case 2, compared with that between Case 2 and Case 3, with the same well screen length difference $(20 \mathrm{~m})$.

\subsubsection{Comparison of the Energy Storage Efficiency among the} Three Cases. The energy flow rates in the cycle operations for the three cases are calculated by the model (Figure 7), the differences within which occur during the production period. 


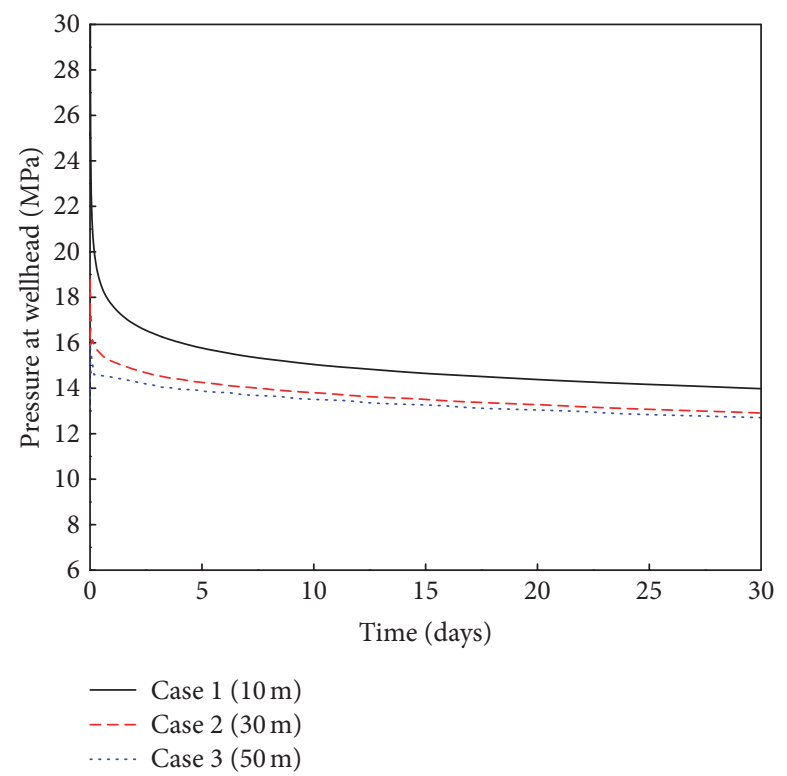

FIGURE 5: Change of pressure at the wellhead with time for the three cases.

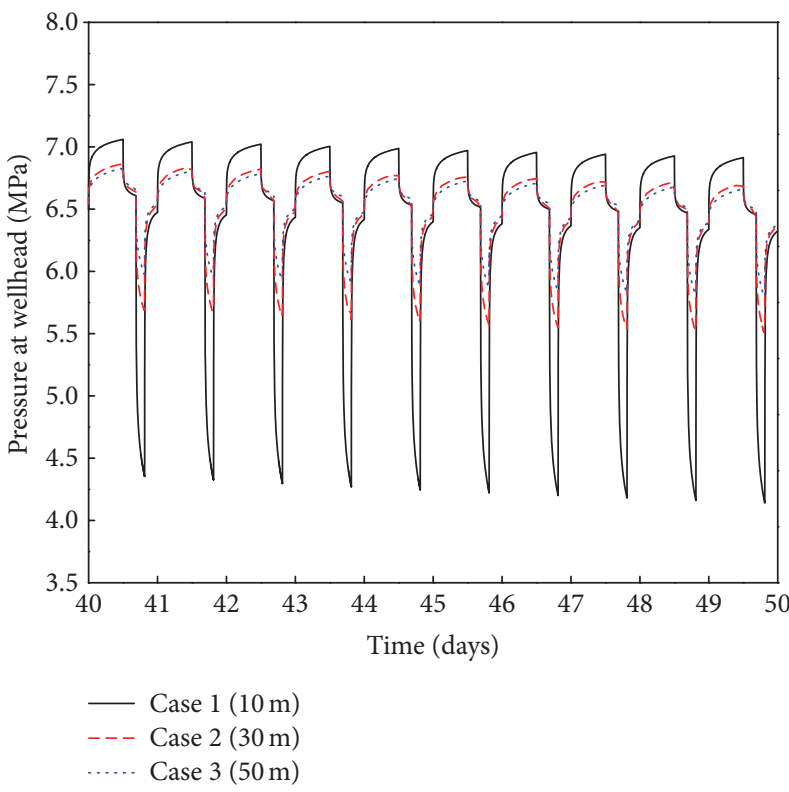

(a)

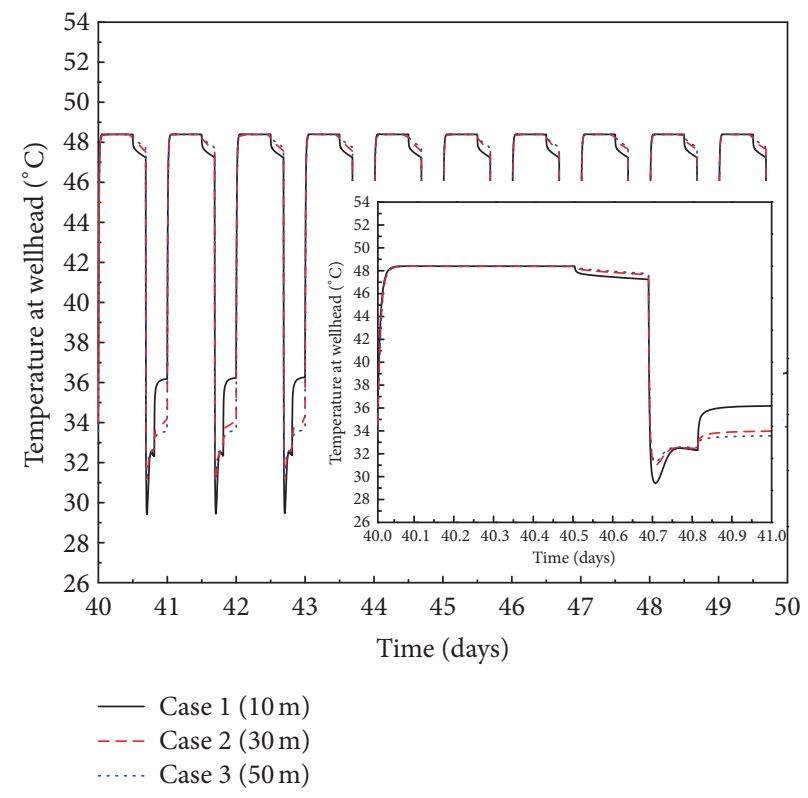

(b)

Figure 6: Comparisons of the variances of pressure and temperature at the wellhead during the cycle processes among the three different well penetrating cases. (a) Pressure. (b) Temperature.

The energy flow rate is slightly higher in the cases with a longer well screen length. The changes in the energy flow rate with time for the three cases are almost consistent with the change in the temperature with time during the production period (Figure 6(b)). More energy can be produced with air at a higher pressure and temperature when using a long well screen length.

Ignoring the efficiencies of the compressor and turbine, we only consider the energy loss from the underground storage vessel caused by the cycle processes. The energy storage efficiency per cycle process can be calculated as follows:

$$
E_{\text {efficiency }}=\frac{E_{\text {Injection }}}{E_{\text {Production }}},
$$

where $E_{\text {efficiency }}$ is the energy efficiency per cycle; $E_{\text {Injection }}$ is the total injection energy; and $E_{\text {Production }}$ is the total production energy.

The energy efficiency gradually increases with the continuation of the cycle, which varies from $93.6 \%$ to $95.4 \%$ over 50 


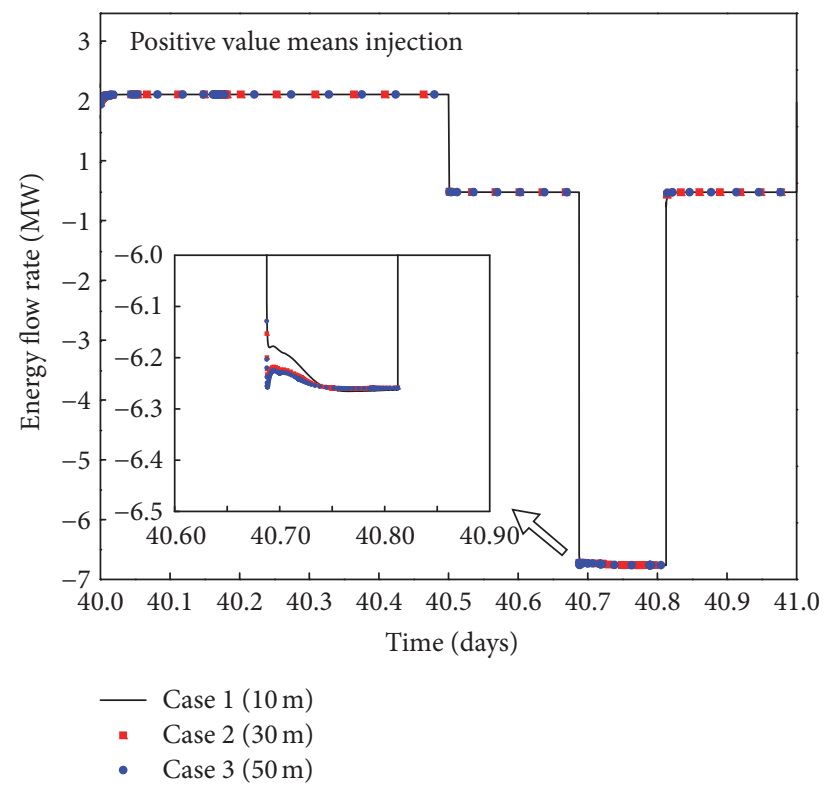

FIgURE 7: The energy flow rates at the wellhead in the three different cases.

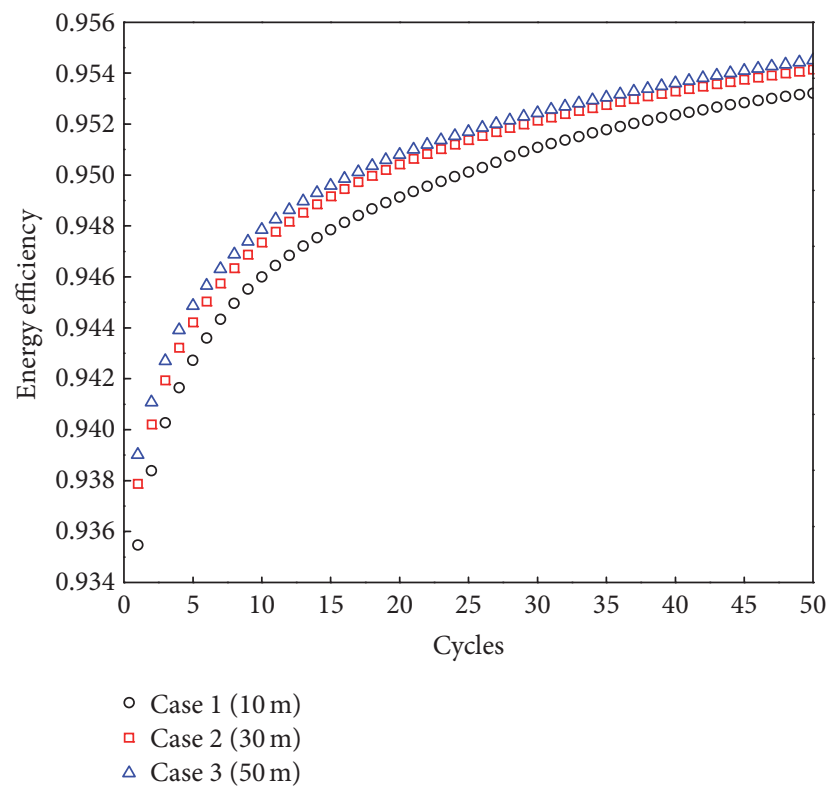

FIGURE 8: Changes of the energy efficiency of the CAESA system in the three different cases with the continuation of cycles.

cycles (Figure 8). The reason for this is that the temperature near the wellbore in the aquifer and in the overlying cap formation will gradually become higher due to heat transfer with the higher temperature injected air, which causes less energy loss over the continued cycle processes. In addition, a longer well screen length performs with slightly better energy efficiency. The energy efficiency in Case 3 is $0.2 \%(13.2 \mathrm{~kW}$ total energy) higher than Case 1 per cycle and the variance is more sensitive to shorter well screen length. Although the differences of the energy efficiency among the three cases are not obvious in this model, the total energy loss can be more

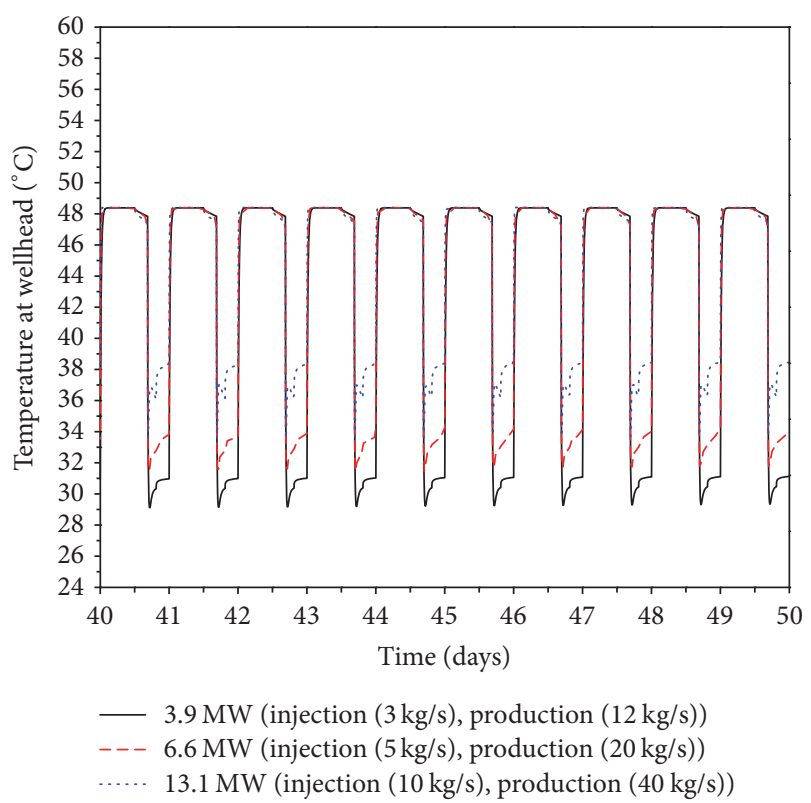

FIGURE 9: Changes in the wellhead temperature with time among the three energy storage scales of the CAESA system.

significant if a large-scale CAESA system is being implemented.

A comparison of the CAESA system performance with the three kinds of well screen lengths penetrating into the aquifer suggests that longer well screen lengths can perform with better energy storage efficiencies, especially for the case penetrating through the entire target aquifer. Additionally, longer well screen length will contribute more stable and sufficiently pressurized output air for the regeneration of electricity. Furthermore, the greater deliverability with a longer well screen could extend the energy storage scale in a single well or reduce the number of wells required for a large-scale CAESA system.

\section{Discussion}

As discussed above, well screens that entirely penetrate through the target aquifer can perform with better energy efficiencies in a CAESA system. In this section, we will investigate the effects of the energy storage scale and reservoir depth under the conditions of a well penetrating through the entire aquifer using numerical modelling.

4.1. Impact of the Energy Storage Scale on the System Performance. In a fixed CAESA system, different energy storage scales can be reflected by variances in the injection and production rates. To evaluate the influences of the energy storage scale, we design three cases of the energy storage scale, the corresponding injection and production rates of which are shown in Table 2. The wellbore is perforated through the entire aquifer. The initial gas bubble and other aquifer parameters are the same as those mentioned previously.

Figure 9 demonstrates the temperature variance among the three cases of the energy storage scale at the wellhead 


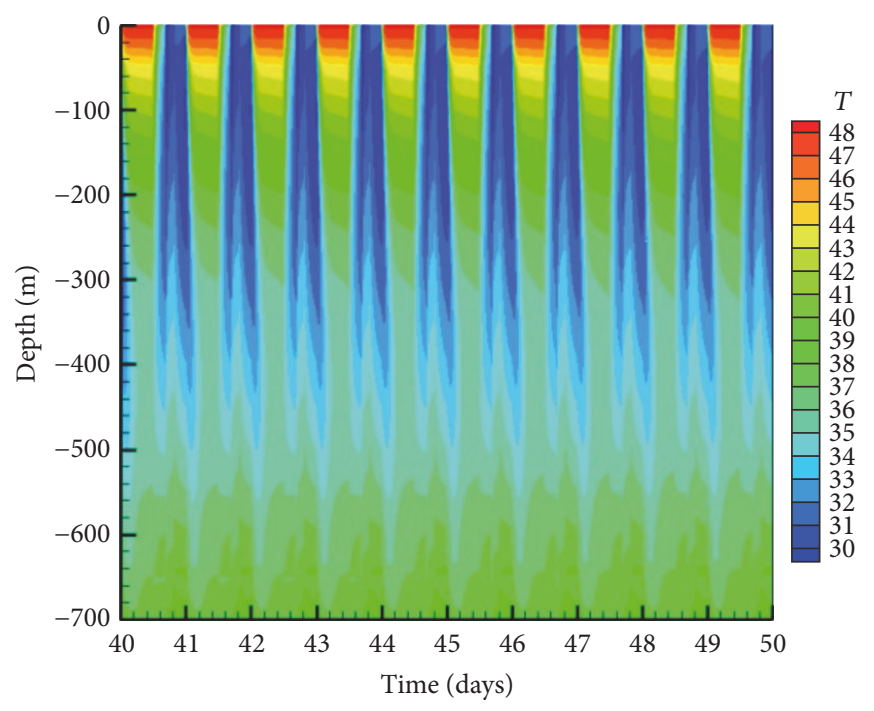

(a)

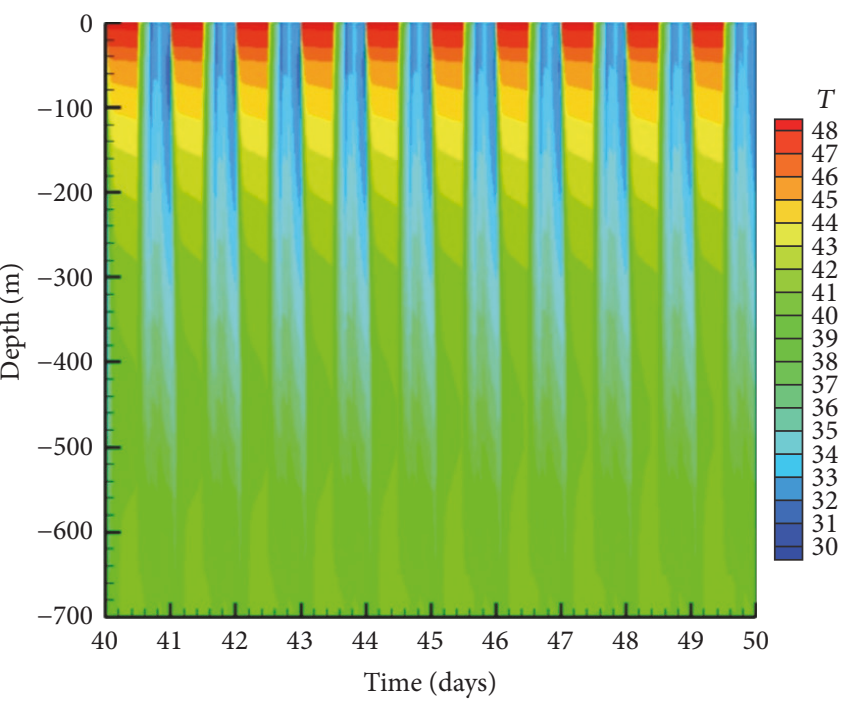

(b)

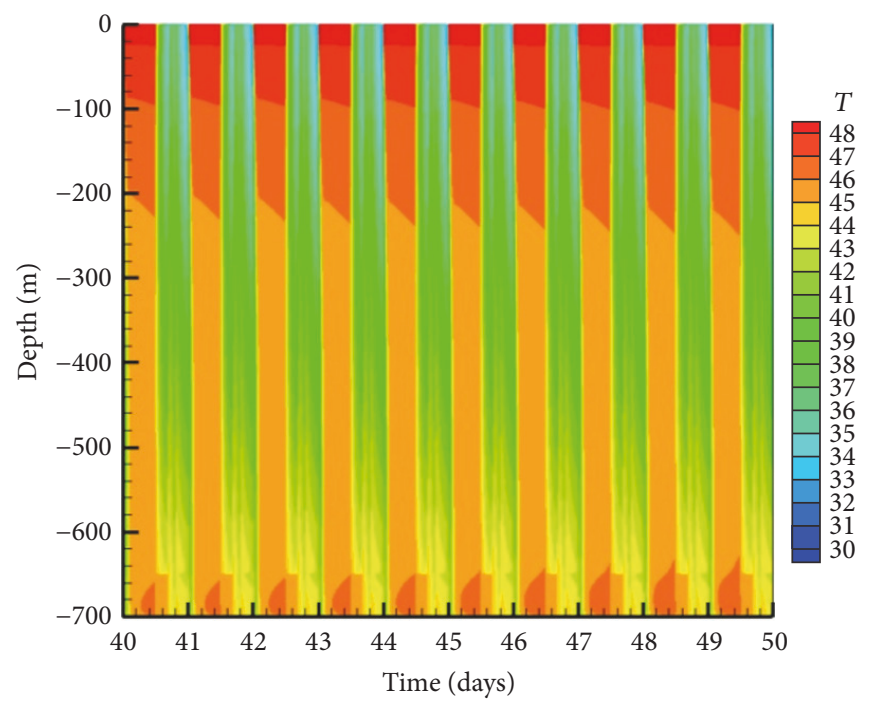

(c)

FIGURE 10: Temperature profiles along the wellbore among the three energy storage scales of the CAESA system during the 40-50 cycles. (a) $3.9 \mathrm{MW}$ (injection $3 \mathrm{~kg} / \mathrm{s}$, production $12 \mathrm{~kg} / \mathrm{s}$ ); (b) $6.6 \mathrm{MW}$ (injection $5 \mathrm{~kg} / \mathrm{s}$, production $20 \mathrm{~kg} / \mathrm{s}$ ); (c) $13.1 \mathrm{MW}$ (injection $10 \mathrm{~kg} / \mathrm{s}$, production $40 \mathrm{~kg} / \mathrm{s})$.

TABLE 2: The injection and production rates in the three energy storage scale systems.

\begin{tabular}{lcc}
\hline Scale $(\mathrm{MW})$ & Injection rate $(\mathrm{kg} / \mathrm{s})$ & Production rate $(\mathrm{kg} / \mathrm{s})$ \\
\hline 3.9 & 3 & 12 \\
6.6 & 5 & 20 \\
13.1 & 10 & 40 \\
\hline
\end{tabular}

during the operation cycle. The minimum wellhead temperature reaches $34^{\circ} \mathrm{C}, 31^{\circ} \mathrm{C}$, and $29^{\circ} \mathrm{C}$ for the $3.9 \mathrm{MW}, 6.6 \mathrm{MW}$, and 13.1 MW scales, respectively. In addition, the maximum temperature is the same (approximately $48^{\circ} \mathrm{C}$ ) in the different cases during the injection period. Larger energy storage scales, which correspond to larger air mass cycles, result in higher air temperatures during the production period.

The temperature profiles along the wellbore during the operation cycle are drawn in Figure 10. The temperature distribution is controlled by heat transfer between the air in the wellbore and the surrounding formation. Taking the injection process as an example, the high-temperature injected air transfers heat to the surrounding cooler formation, which results in a temperature drop in the wellbore. As the depth increases, the temperature in the surrounding formation rises and the temperature difference with the air in the wellbore could decrease. When the temperature in the surrounding formation is higher (the temperature can reach $42^{\circ} \mathrm{C}$ at the bottom of the aquifer as calculated by the aforementioned geothermal gradient) than the air temperature in the wellbore 


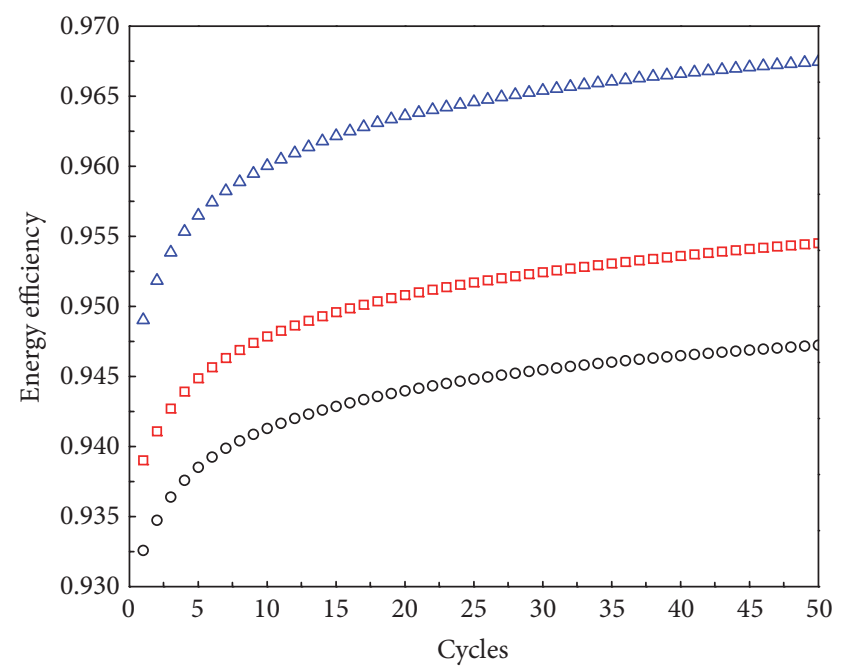

- $3.9 \mathrm{MW}$ (injection $(3 \mathrm{~kg} / \mathrm{s})$, production $(12 \mathrm{~kg} / \mathrm{s})$ )

口 $6.6 \mathrm{MW}$ (injection $(5 \mathrm{~kg} / \mathrm{s})$, production $(20 \mathrm{~kg} / \mathrm{s})$ )

$\Delta 13.1 \mathrm{MW}$ (injection $(10 \mathrm{~kg} / \mathrm{s})$, production $(40 \mathrm{~kg} / \mathrm{s})$ )

(a)

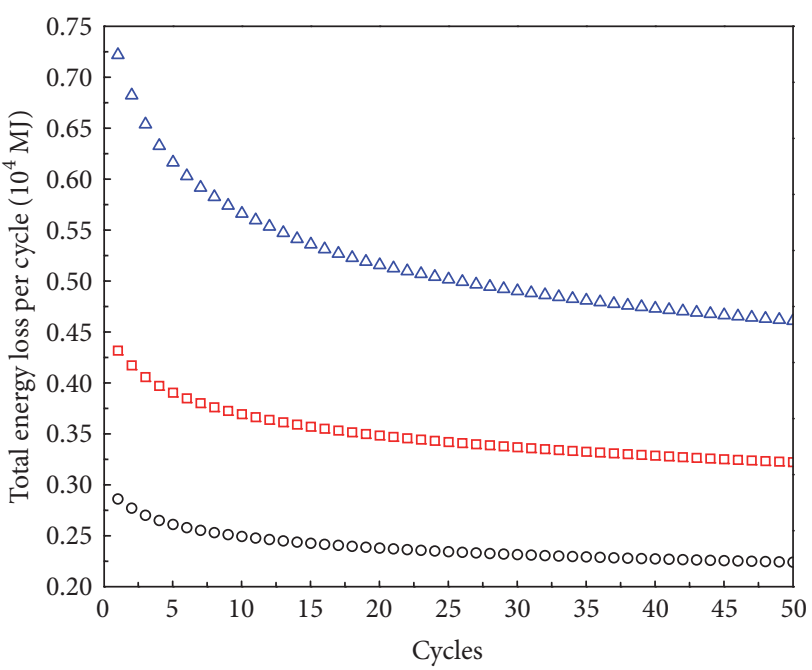

- $3.9 \mathrm{MW}$ (injection $(3 \mathrm{~kg} / \mathrm{s})$, production $(12 \mathrm{~kg} / \mathrm{s})$ )

口 $6.6 \mathrm{MW}$ (injection $(5 \mathrm{~kg} / \mathrm{s})$, production $(20 \mathrm{~kg} / \mathrm{s})$ )

$\triangle 13.1 \mathrm{MW}$ (injection $(10 \mathrm{~kg} / \mathrm{s})$, production $(40 \mathrm{~kg} / \mathrm{s})$ )

FIGURE 11: Comparison of the energy efficiencies and total energy losses during the 50 cycles under the three energy storage scales of a CAESA system. (a) Energy efficiency. (b) Total energy loss.

(in the 3.9 MW and 6.6 MW cases), the heat transfer process is reversed, which means that heat will be transferred to the wellbore from the surrounding formation. In the 3.9 MW and 6.6 MW cases, the temperature drops and then rises with depth along the wellbore during the injection. During the operation cycle, a larger energy storage scale represents a higher temperature distribution. The difference could be explained as the consequence of the larger air flow velocity in the wellbore relative to larger energy storage scales, which will cause a smaller heat loss of the unit air mass to the surrounding formation.

The variances in the energy efficiency and total energy loss during the 50 cycles in the three energy storage scales are described in Figure 11. A larger energy storage scale can cause a greater total energy loss in a CAESA system. However, the case with the $13.1 \mathrm{MW}$ scale has a better energy storage efficiency (96.8\%) when compared with those at the 6.6 MW scale $(95.3 \%)$ and $3.9 \mathrm{MW}$ scale $(94.5 \%)$ in the 50th cycle. The opposite trends between the energy efficiency and total energy loss are caused by the total energy storage scale. The ratio of the total energy loss in these different cases is smaller than the ratio of the energy storage scale, which means that the energy loss of the unit air mass is smaller in larger energy storage scales, which can be reflected by the temperature variances during the cycle (see Figures 9 and 10) due to larger air flow velocities. Under the condition of guaranteeing the sustainability of the system, these numerical results reveal that a larger energy storage scale design could perform with better energy efficiency.

4.2. Impact of the Reservoir Depth on the System Performance. In this section, we will discuss the reservoir depth impact on the CAESA system performance. Different reservoir depths
TABLE 3: Scenario sets for different target aquifer depths in a CAESA system.

\begin{tabular}{lc}
\hline Case & Target aquifer location depth \\
\hline Case 4 & $150 \mathrm{~m}-200 \mathrm{~m}$ \\
Case 5 & $250 \mathrm{~m}-300 \mathrm{~m}$ \\
Case 6 & $450 \mathrm{~m}-500 \mathrm{~m}$ \\
Case 7 & $650 \mathrm{~m}-700 \mathrm{~m}$ \\
Case 8 & $850 \mathrm{~m}-900 \mathrm{~m}$ \\
\hline
\end{tabular}

could impact both the performance of the initial gas bubble formation and changes in the pressure and temperature. At the same time, we further investigate the interaction between geothermal and CAESA systems, as shown in the previous section. Five different target aquifer depth cases are investigated as shown in Table 3 . The thickness of the target aquifer remains constant $(50 \mathrm{~m})$ and the ranges in their values represent the location depth. The selection ranges for the target aquifer location depths are based on the literature, which suggests that the depth to the top of the aquifer should be larger than $140 \mathrm{~m} \mathrm{[2].} \mathrm{The} \mathrm{other} \mathrm{basic} \mathrm{parameters} \mathrm{of} \mathrm{the}$ aquifer are the same as above, and the overlying formation is impermeable. The wellbore entirely penetrates the target aquifer. The grid is generated depending on the different cases with the same resolution in the aquifer.

Different depths of the target aquifer will produce different initial gas bubbles. During the first stage, the initial gas bubble is generated using the simulator. The injection scheme is the same as that mentioned previously $(50 \mathrm{~kg} / \mathrm{s}$ for 30 days) among the five cases. Figure 12 illustrates the gas saturation distribution after injection for the different cases. The gas saturation distribution only shows minor differences 


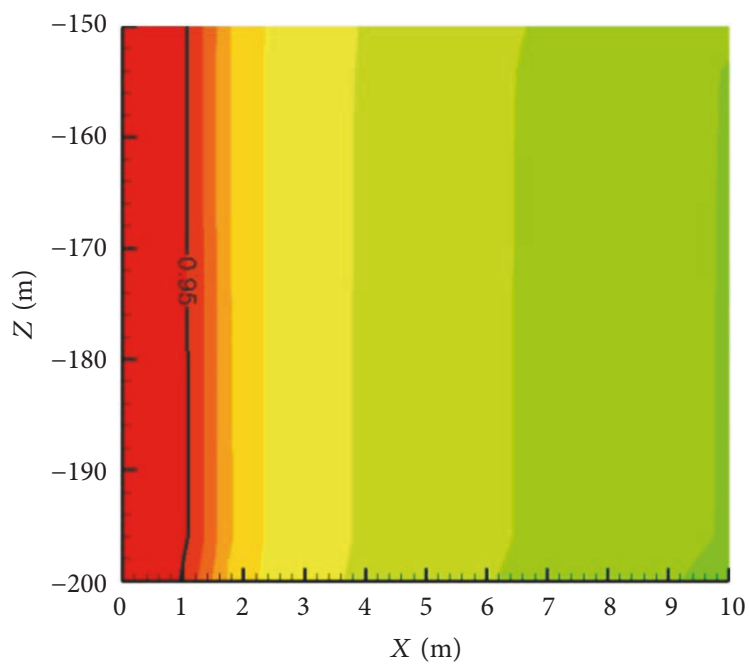

(a)

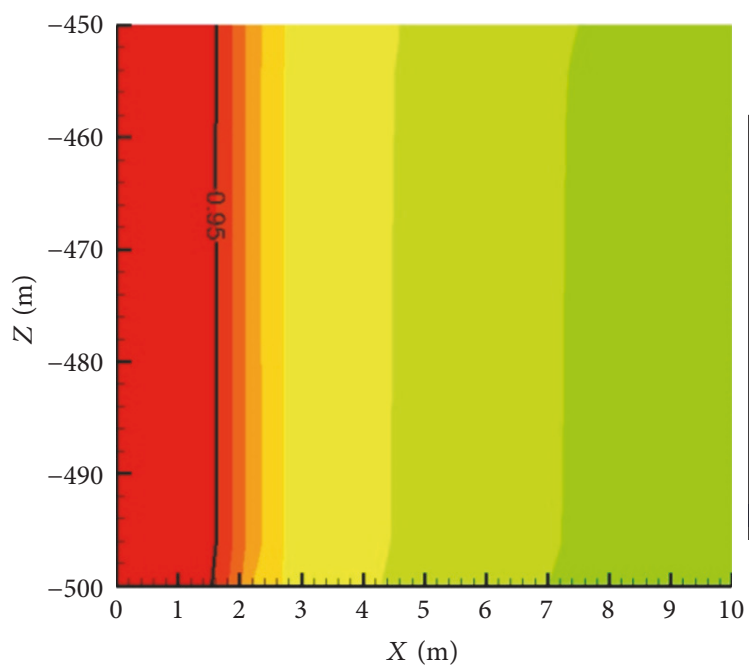

(c)

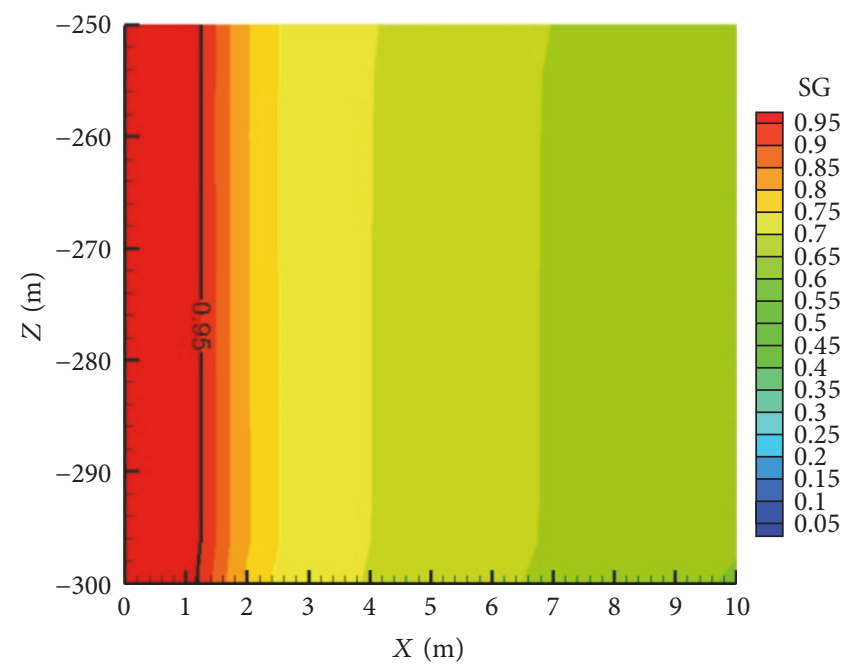

(b)

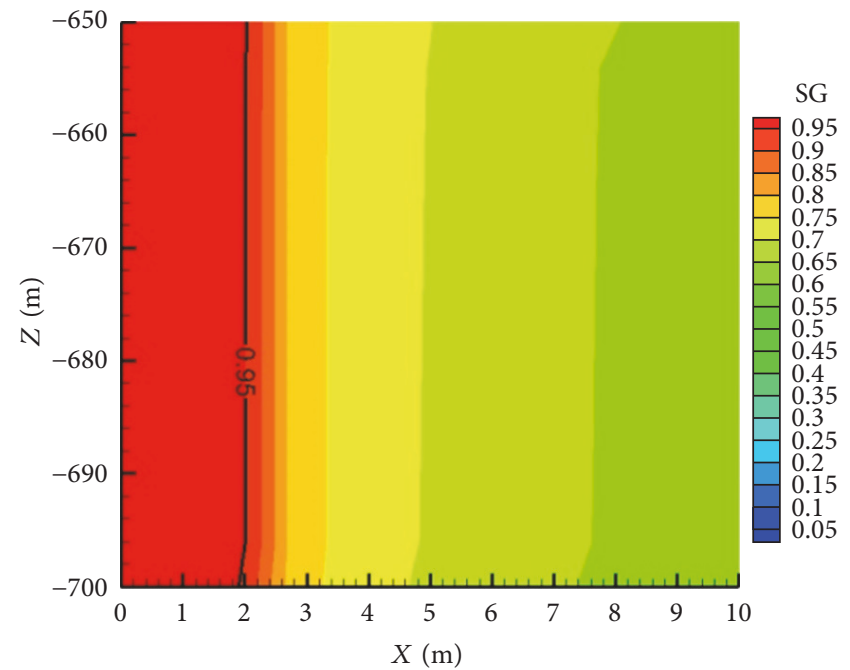

(d)

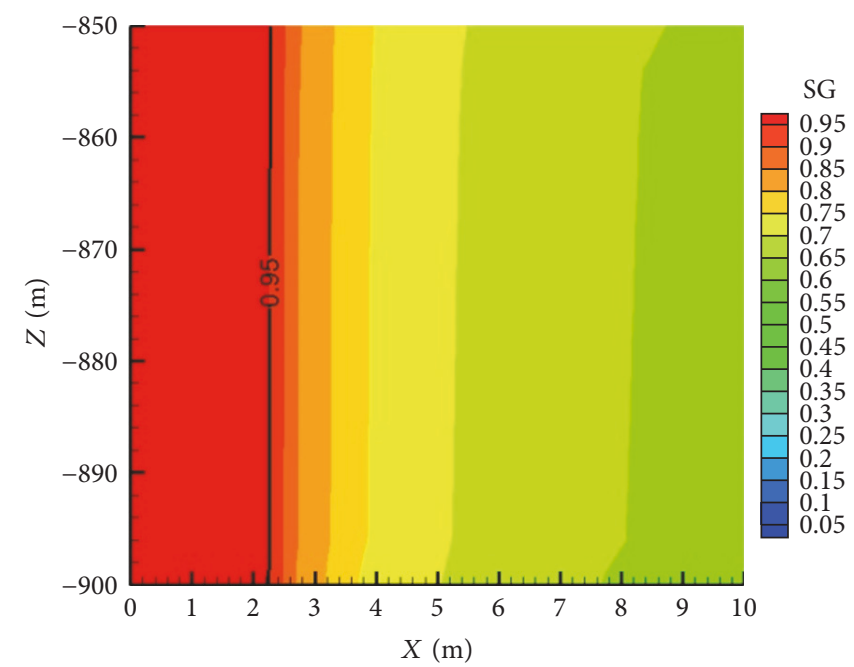

(e)

FIGURE 12: Distribution of the initial gas saturation within a lateral distance of $10 \mathrm{~m}$ before the cycle process for five cases. (a) Case 4 (150 m-200 m); (b) Case 5 (250 m-300 m); (c) Case 6 (450 m-500 m); (d) Case 7 (650 m-700 m); (e) Case 8 (850 m-900 m). 


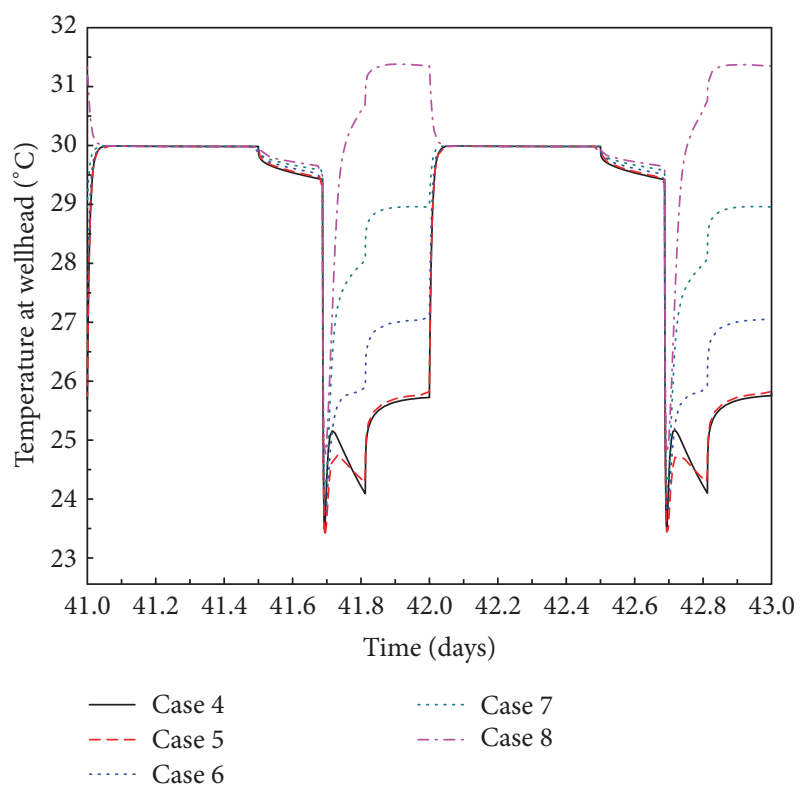

FIGURE 13: Comparison of the temperate changes at the wellhead during the operation cycle processes among the five depth cases.

for the five cases. As the 0.95 gas saturation contour shows, larger distances away from the wellbore are observed in the deeper cases, and they vary from $1 \mathrm{~m}$ for Case 4 to $2.2 \mathrm{~m}$ for Case 8 . This could be explained insomuch that greater depths correlate to higher storage densities and a smaller plume area, which makes the gas accumulate near the wellbore.

Within the cycle process, we design the cycle scheme as the basic model $(5 \mathrm{~kg} / \mathrm{s}$ injection for $12 \mathrm{~h}$ and $20 \mathrm{~kg} / \mathrm{s}$ production for $3 \mathrm{~h}$ ). The injection air temperature is set to $30^{\circ} \mathrm{C}$, which is different from the temperature in the base model, in consideration of the geothermal gradient $\left(38.5^{\circ} \mathrm{C} / \mathrm{km}\right)$ and the different depth cases. A comparison of the wellhead temperature changes in 41-43 days after the start of the operation cycle is shown in Figure 13. As the in situ temperature in the formation increases with depth, the heat in the wellhead can be replenished from the formation when the temperature in the formation is higher than the injection air temperature. This can result in the fact that the wellhead temperature is higher in deeper cases, and it even reaches a temperature that is higher than the injection temperature during the production period in Case 8 .

Figure 14 displays the temperature profile at the wellhead in the 40th cycle for the five cases. For Case 4 and Case 5, the background temperature (i.e., the undisturbed formation temperature) is lower than the injection air temperature. Therefore, in the entire operation cycle, the heat will constantly flow into the surrounding formation. With an increase in the depth (from Case 6 to Case 8), the background temperature will gradually become higher than the injection temperature $\left(30^{\circ} \mathrm{C}\right)$, which may reverse the heat transfer process at certain depths, and the injected air could be heated by the geothermal.

The energy efficiencies in the five depth cases are drawn in Figure 15. A CAESA system with a deeper aquifer performs with better energy efficiency. The differences may be caused by two main reasons. First is the effect of the geothermal. Heat is lost to the surrounding cooler formation when the background temperature in the aquifer is lower (Figures 14(a) and 14(b) for Case 4 and Case 5, resp.). A deeper aquifer system will enlarge the area of the heat loss, which may result in a worse energy efficiency (the energy efficiency in Case 4 will become better than Case 5 with the continuation of the cycle). When the background temperature is higher (Figures 14(c), 14(d), and 14(e) for Cases 6, 7, and 8, resp.), a longer wellbore with a deeper aquifer will reduce the heat loss and sometimes can obtain thermal supplement from surrounding formation, which can result in better energy efficiency in a CAESA system. Second reason could be the higher energy storage densities and pressure. Greater depths correlate to higher storage densities and a smaller gas diffusion area could decrease the energy loss and higher storage pressure could maintain the thermal energy by compression heat. The two reasons result in the fact that the energy efficiency can be approached $100 \%$ in Case 8 . We can also infer that the energy efficiency may exceed $100 \%$ with a deeper aquifer system and higher in situ temperature. These results show that a deeper target aquifer with an entirely perforated wellbore could perform with a better energy efficiency, which could reduce the heat loss and obtain thermal supplement by higher surrounding formation temperature and decrease the energy loss by large storage densities and high pressure. However, in practical engineering applications, a CAESA system with a deeper target aquifer may increase the cost for well drilling, which means the total economic performance needs to be considered.

However, there are two aspects of limitations in this study. First, in the conceptual model, the aquifer is assumed to be horizontal, homogeneous, and embedded with the impermeable formation. While in the natural condition, the aquifer is often heterogeneous, which may affect the initial gas bubble distribution and the pressure variance in cycle process. Also the energy efficiency can become worse caused by gas loss with the poor Caprock. Second, in the T2WELL/EOS3 module, the gas is considered as ideal gas. The property differences between ideal gas and real gas may affect the simulation results. The permeability and porosity variance, as well as the possible hazards caused by pressure build-up, will not be considered as the mechanics process is ignored in the module. Despite the limitations existing in this study, it can answer the foundation questions about the wellbore influence in the CAESA system mentioned in the paper.

\section{Conclusions}

A wellbore-reservoir numerical model was developed to evaluate the influence of wellbore flow on the performance of a CAESA system. The integrated operation processes, including the formation of the initial gas bubble formation and the cycle injection and production process, were simulated in detail. A wellbore that is fully penetrating into the target aquifer can provide the most reliable pressurized air output, and a comparison of the energy efficiency calculated using the ratio of input energy and output energy from the storage 


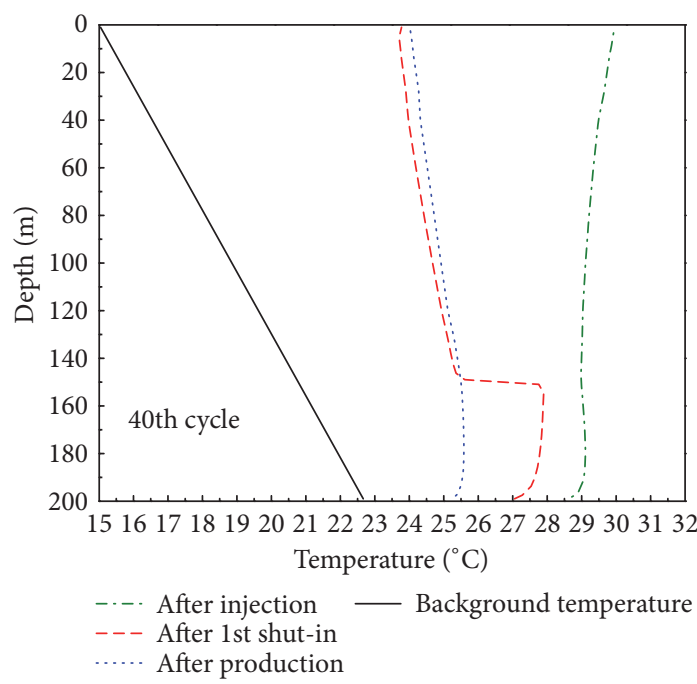

(a)

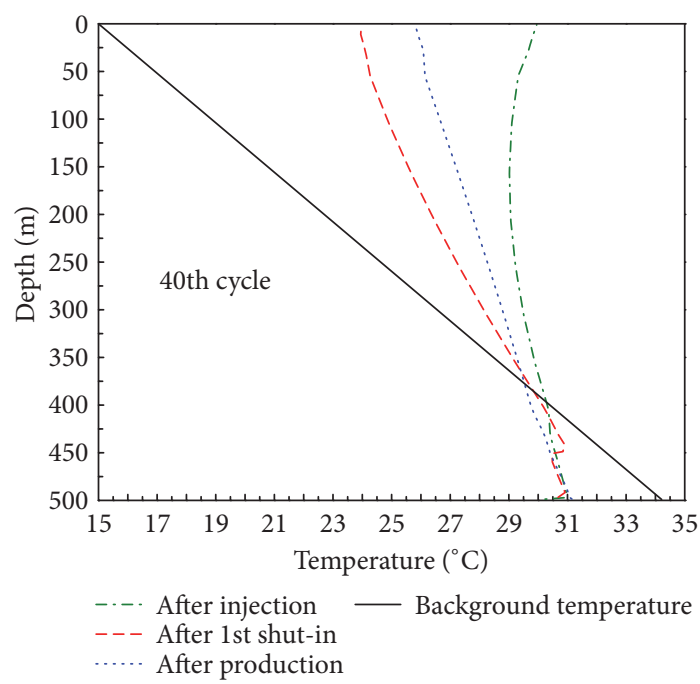

(c)

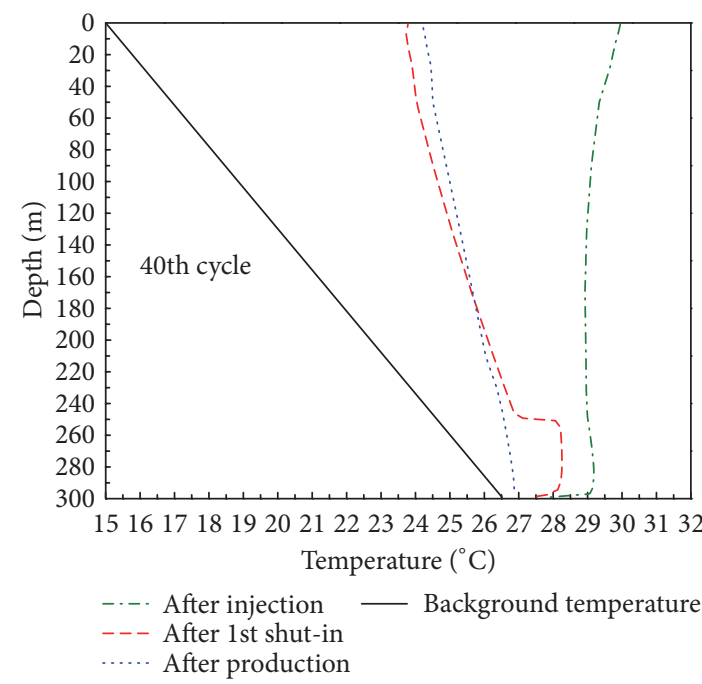

(b)

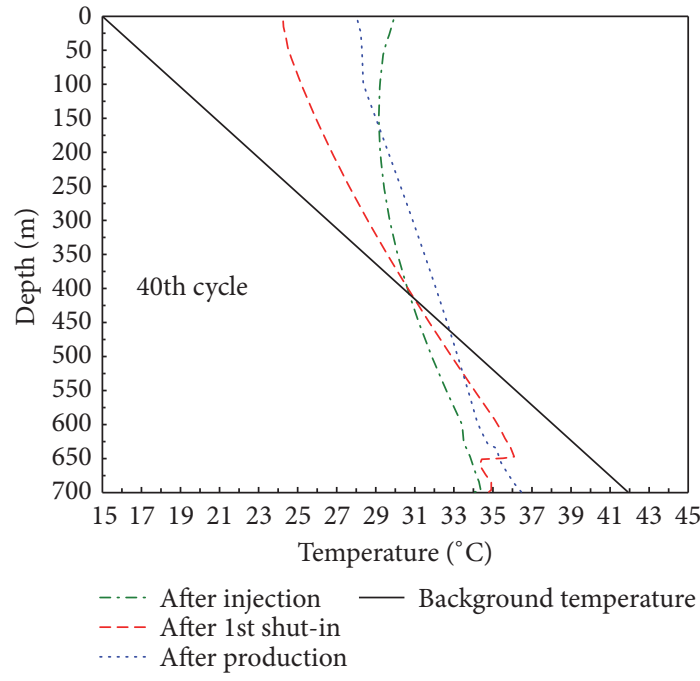

(d)

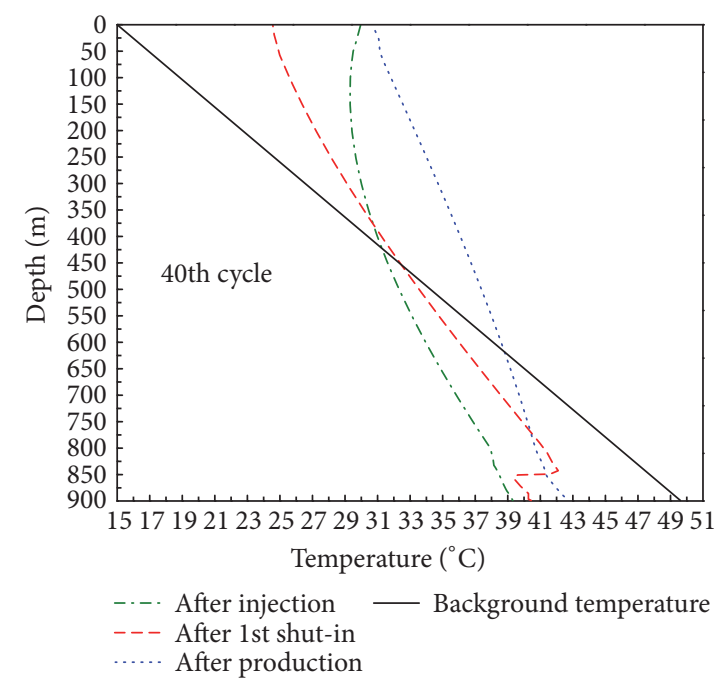

(e)

FiguRE 14: The temperature profiles along the wellbore in the 40th cycle for the different cases. (a) Case 4 (150-200 m); (b) Case 5 (250-300 m); (c) Case 6 (450-500 m); (d) Case 7 (650-700 m); (e) Case 8 (850-900 m). 


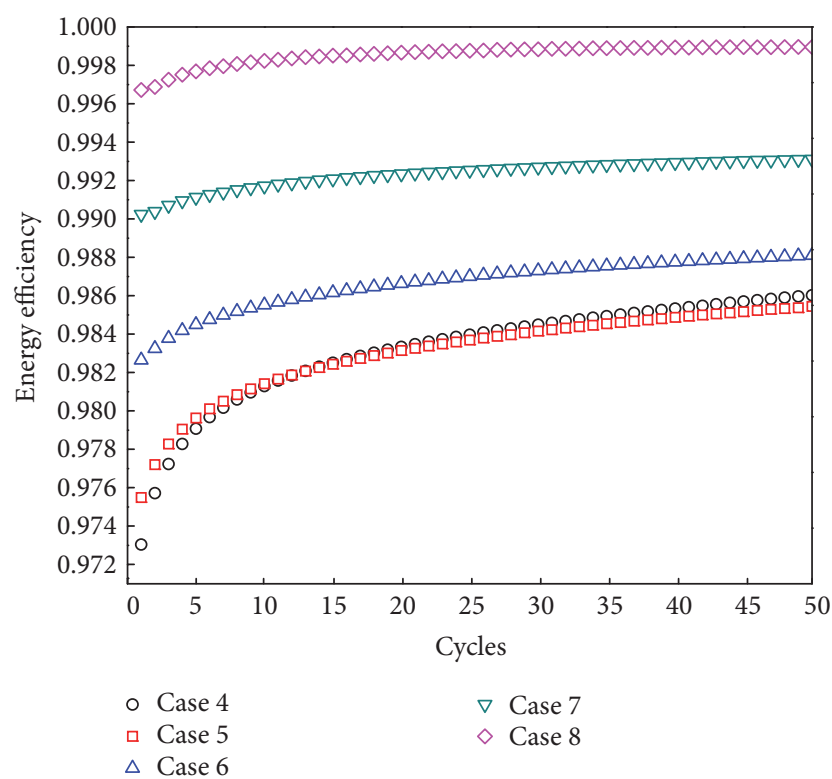

FIGURE 15: Comparison of the energy efficiencies in the continued cycles among the five depth cases.

vessel shows that it can help improve the performance of a CAESA system due to heat transfer with the formation.

On the basis of the wellbore study results, the impacts of the energy storage scale and reservoir depth on the performance of a CAESA system were investigated through numerical modelling. The results show that larger energy storage scales with larger injection and production rates can help improve the performance of a CAESA system, which is represented by a smaller energy loss to the surrounding formation relative to the unit air mass. The geothermal effect and energy storage density can impact the total energy efficiency, and a deeper target aquifer can improve the performance of a CAESA system. The results can help the system design and extend the prospects of CAESA system combined with geothermal system.

There still remain some problems concerning the influences of wellbore flow on a CAESA system, which need to be studied in the future. One important challenge is how to build an initial gas bubble at a larger scale, which can support larger scale energy storages. In addition, the impact of geothermal effect on CAES is an interesting research issue and should be further studied. Other inevitable aspects, including the reaction of oxygen with minerals, the corrosion of the wellbore, and the associated risk assessments, should be investigated.

\section{Conflicts of Interest}

The authors declare that there are no conflicts of interest regarding the publication of this paper.

\section{Acknowledgments}

This research was funded by the Fundamental Research Funds for the Central Universities through Beijing Normal University (no. 2015KJJCB17) and the National Natural
Science Foundation of China (Grant no. 41572220). It was also supported by the China Scholarship Council (CSC) for the first author's visit to the Lawrence Berkeley National Laboratory.

\section{References}

[1] M. Budt, D. Wolf, R. Span, and J. Yan, "A review on compressed air energy storage: Basic principles, past milestones and recent developments," Applied Energy, vol. 170, pp. 250-268, 2016.

[2] S. Succar and R. H. Williams, "Compressed air energy storage: theory, resources, and applications for wind power," Princeton Environmental Institute report, p. 8, 2008.

[3] R. Allen, T. Doherty, and L. Kannberg, "Summary of selected compressed air energy storage studies," Tech. Rep. PNL-5091, 1985.

[4] D. R. Mack, "S omething new in power technology," IEEE Potentials, vol. 12, no. 2, pp. 40-42, 1993.

[5] F. Crotogino, K. U. Mohmeyer, and R. Scharf, Huntorf CAES: More than 20 Years of Successful Operation, Orlando, Florida, USA, 2001.

[6] R. Kushnir, A. Dayan, and A. Ullmann, "Temperature and pressure variations within compressed air energy storage caverns," International Journal of Heat and Mass Transfer, vol. 55, no. 2122, pp. 5616-5630, 2012.

[7] M. Raju and S. Kumar Khaitan, "Modelling and simulation of compressed air storage in caverns: a case study of the Huntorf plant," Applied Energy, vol. 89, no. 1, pp. 474-481, 2012.

[8] E. Barbour, D. Mignard, Y. Ding, and Y. Li, "Adiabatic Compressed Air Energy Storage with packed bed thermal energy storage," Applied Energy, vol. 155, pp. 804-815, 2015.

[9] N. Hartmann, O. Vöhringer, C. Kruck, and L. Eltrop, "Simulation and analysis of different adiabatic Compressed Air Energy Storage plant configurations," Applied Energy, vol. 93, pp. 541548, 2012.

[10] J. Rutqvist, H.-M. Kim, D.-W. Ryu, J.-H. Synn, and W.-K. Song, "Modeling of coupled thermodynamic and geomechanical performance of underground compressed air energy storage in lined rock caverns," International Journal of Rock Mechanics and Mining Sciences, vol. 52, pp. 71-81, 2012.

[11] C. Bullough, C. Gatzen, C. Jakiel, M. Koller, A. Nowi, and S. Zunft, "Advanced adiabatic compressed air energy storage for the integration of wind energy," in European Wind Energy Conference, EWEC, vol. 22, p. 25, London, UK, 2004.

[12] Z. Guo, G. Deng, Y. Fan, and G. Chen, "Performance optimization of adiabatic compressed air energy storage with ejector technology," Applied Thermal Engineering, vol. 94, pp. 193-197, 2016.

[13] X. Luo, J. Wang, C. Krupke et al., "Modelling study, efficiency analysis and optimisation of large-scale Adiabatic Compressed Air Energy Storage systems with low-temperature thermal storage," Applied Energy, vol. 162, pp. 589-600, 2016.

[14] M. Sánchez, A. Shastri, and T. M. Le, "Coupled hydromechanical analysis of an underground compressed air energy storage facility in sandstone," Geotechnique Letters, vol. 4, no. AprilJune, pp. 157-164, 2014.

[15] C. M. Oldenburg and L. Pan, "Porous Media CompressedAir Energy Storage (PM-CAES): Theory and Simulation of the Coupled Wellbore-Reservoir System," Transport in Porous Media, vol. 97, no. 2, pp. 201-221, 2013. 
[16] C. M. Oldenburg and L. Pan, "Utilization of CO2 as cushion gas for porous media compressed air energy storage," Greenhouse Gases: Science and Technology, vol. 3, no. 2, pp. 124-135, 2013.

[17] C. Guo, K. Zhang, C. Li, and X. Wang, "Modelling studies for influence factors of gas bubble in compressed air energy storage in aquifers," Energy, vol. 107, pp. 48-59, 2016.

[18] C. Guo, L. Pan, K. Zhang, C. M. Oldenburg, C. Li, and Y. $\mathrm{Li}$, "Comparison of compressed air energy storage process in aquifers and caverns based on the Huntorf CAES plant," Applied Energy, vol. 181, pp. 342-356, 2016.

[19] A. S. Jarvis, Feasibility study of porous media compressed air energy storage in South Carolina, United States of America, Clemson University, 2015.

[20] Schulte R. H., N. Critelli, K. Holst, and G. Huff, Lessons from Iowa: development of a 270 Megawatt compressed air energy storage project in midwest independent system operator, Sandia National Laboratories, Albuquerque, New Mexico, USA, 2012.

[21] B. McGrail, J. Cabe, C. Davidson et al., Technoeconomic performance evaluation of compressed air energy storage in the Pacific Northwest, Pacific Northwest National Laboratory, Richland, USA, 2013.

[22] R. Kushnir, A. Ullmann, and A. Dayan, "Compressed air flow within aquifer reservoirs of CAES plants," Transport in Porous Media, vol. 81, no. 2, pp. 219-240, 2010.

[23] R. Kushnir, A. Ullmann, and A. Dayan, "Thermodynamic and hydrodynamic response of compressed air energy storage reservoirs: a review," Reviews in Chemical Engineering, vol. 28, no. 2-3, pp. 123-148, 2012.

[24] L. Pan and C. M. Oldenburg, "T2well-an integrated wellborereservoir simulator," Computer Geosiciences, vol. 65, pp. 46-55, 2014.

[25] Y. Li, K. Zhang, L. Hu, and J. Wang, “Thermodynamic analysis of heat transfer in a wellbore combining compressed air energy storage," Environmental Earth Sciences, vol. 6, no. 76, pp. 1-10, 2017.

[26] K. Pruess, C. Oldenburg, and G. Moridis, “TOUGH2 User's Guide Version 2," Tech. Rep. LBNL-43134, Lawrence Berkeley National Laboratory, Berkeley, Calif, USA, 1999.

[27] L. Pan, Wingridder-an interactive grid generator for TOUGH2, Lawrence Berkeley National Laboratory, Berkeley, USA, 1999.

[28] Y. Li, Y.-F. Chen, G.-J. Zhang, Y. Liu, and C.-B. Zhou, "A numerical procedure for modeling the seepage field of watersealed underground oil and gas storage caverns," Tunnelling and Underground Space Technology, vol. 66, pp. 56-63, 2017.

[29] M. Liu, Y. Chen, K. Wei, and C. Zhou, "Interpretation of gas transient pulse tests on low-porosity rocks," Geophysical Journal International, vol. 210, no. 3, pp. 1845-1857, 2017. 

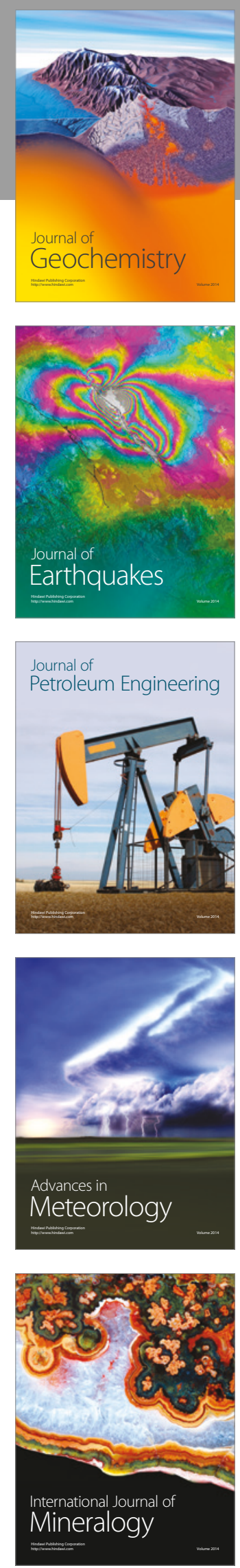
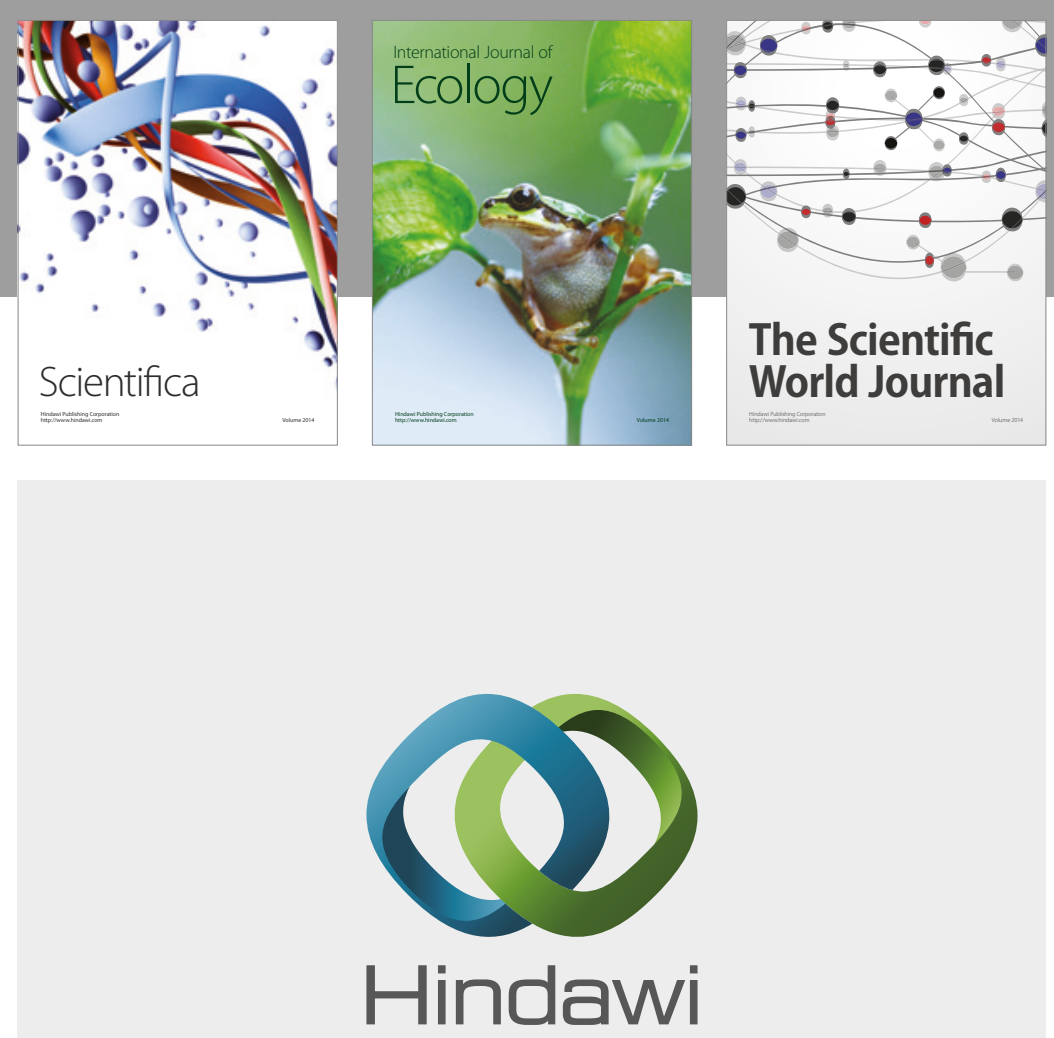

Submit your manuscripts at

https://www.hindawi.com
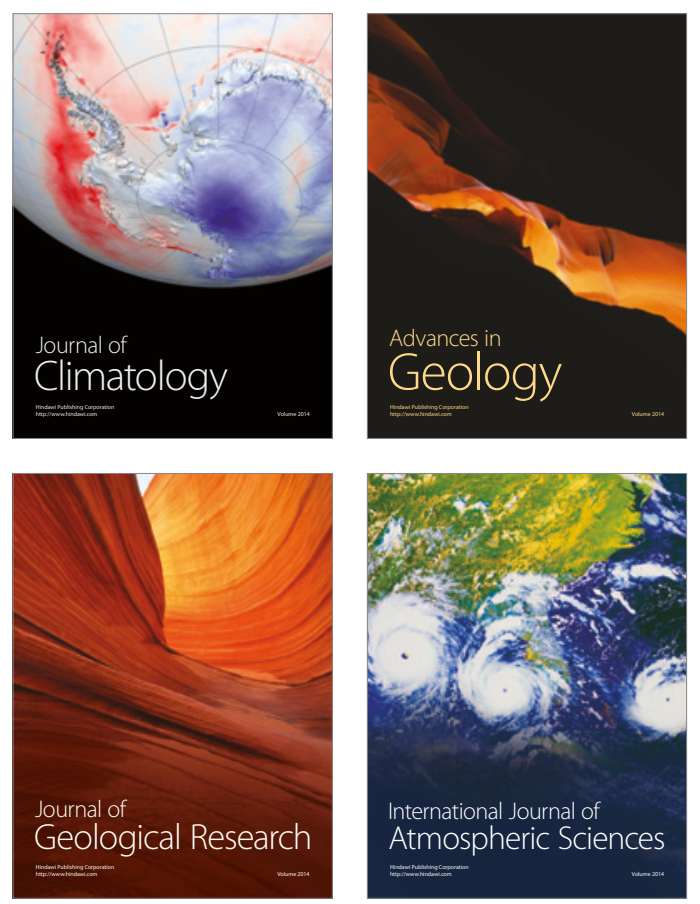

The Scientific

World Journal
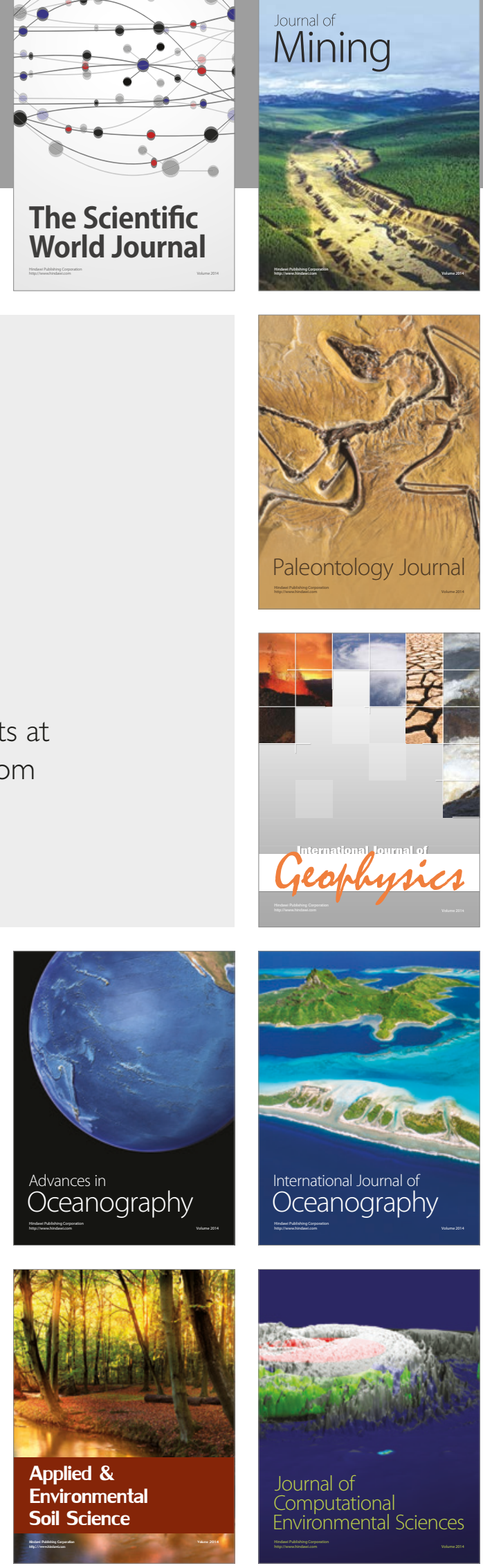